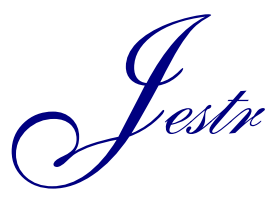

Journal of Engineering Science and Technology Review 12 (2) (2019) 27 - 33

Research Article
JOURNAL OF

Engineering Science and

Technology Review

\title{
Analysis of Integrity of Wellbore Structure in Soft Mudstone during Drilling and Cementing
}

\author{
Xuan Zhao ${ }^{1,2^{*}}$ \\ ${ }^{I}$ College of Pipeline and Civil Engineering, China University of Petroleum, Qingdao 266580, China \\ ${ }_{2}^{2}$ International Petroleum Company Colombia Branch, China Petroleum \& Chemical Corporation, Bogotá 110741, Colombia
}

Received 2 February 2019; Accepted 30 April 2019

\begin{abstract}
The integrity of wellbore structures, which is the basis of oil and gas production in soft mudstone, is significantly affected by drilling and cementing. A coupling wellbore structural model of casing-cement sheath-mudstone formation was proposed in this study to study the mechanism of wellbore structural instability during drilling and cementing. Plastic softening and elastic modulus hardening models were employed to describe the constitutive relationship of soft mudstone and cement sheath, respectively. The plastic damage of near-wellbore formation and cement sheath in the physical processes, namely, drilling, casing down, cement slurry injection, and hardening, was numerically analyzed with different fluid pressures and boundary loads on the wellbore. Results demonstrate that drilling and seepage-stress coupling are the important mechanisms of wellbore structural instability in soft mudstone. Furthermore, cementing and cement hardening can further promote the plastic damage of the soft mudstone near the wellbore, with a $10 \%$ increase range. The tensile hoop and the radial compressive stresses during cementing, which lead to the cement sheath's fracture leakage, are the main reasons of cement sheath failure. Meanwhile, a cement slurry system with low elastic modulus and high Poisson's ratio can maintain the integrity of the wellbore structure in subsequent production and operation. The proposed method provides a certain reference for optimizing construction parameters and cement slurry systems during drilling and cementing.
\end{abstract}

Keywords: Integrity of wellbore structure, Process of drilling and cementing, Seepage-stress coupling

\section{Introduction}

The exploitation and development scales of unconventional oil, gas, and geothermal resources are expanding. The hydrocarbon release caused by low-quality cement and wellbore structural failure presents rapidly rising trend. Therefore, the importance of wellbore structural integrity analysis in oil and gas production is becoming increasingly highlighted [1-2].

Traditional wellbore structural integrity evaluation mainly aims at oil well production and operation stages without considering wellbore construction processes, such as well drilling and well cementing. Plastic damage is influenced by wellbore pressure, non-uniform ground stress, slurry flow in well drilling and cementing, formation creeping/nonlinear deformation, and temperature change. Damage may be generated at cement sheath and formation near wellbore in the well drilling and cementing process, thereby posing a severe threat to wellbore structural safety during the subsequent operation stage, and the problem is especially prominent at sensitive soft mudstone formation [3]. However, wellbore construction involves a series of complicated factors, including multimedium/interfacial structures, nonlinear deformation, temperature/fluid/stress coupling, and loading/unloading history of construction and production. These factors constitute enormous challenges to

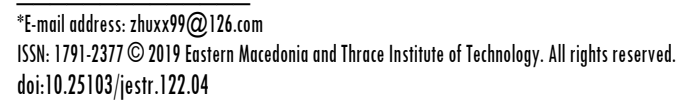

studies regarding wellbore structural integrity in well drilling and cementing.

Scholars have performed numerous studies on wellbore structural integrity in the well drilling and cementing process and its influence factors [4-11]. However, they considered the effect of operating load on wellbore structures in only a specific stage and did not take well drilling and cementing for analysis. As such, the evaluation results of wellbore structural integrity cannot truly reflect wellbore stress and deformation in field operation, and existing methods have great limitations for sensitive mudstone-type formation with low-intensity and high-plasticity mechanical characteristics. Therefore, establishing an analytical model for wellbore structural integrity and analyzing the influence factors in the physical processes-well drilling, casing down and cement paste injection, and hardening are problems requiring urgent solutions.

Based on the above analysis, a coupling wellbore structural model of casing-cement sheath-mudstone formation is established, and wellbore numerical algorithm of multiple physical processes is used to analyze damage evolution of mudstone nearby the well and its influence factors, aiming at providing a reference for soft mudstone wellbore integrity control technology.

\section{State of art}

Scholars all over the world have used multiple means like theoretical analysis, experimental analysis and finite element 
simulation to investigate wellbore structural integrity at present.

On the basis of a laboratory test, Goodwin et al. [4] simulated the generation process of radial cracks on a casing-cement sheath structure caused by internal pressure and temperature expansion; they also studied the influence of low-intensity tough cement material on the airtightness of cement sheath. However, the influences of ground stress and operating load are not considered in this study. On the basis of a plane strain coupling model of a casing pipe-cement sheath-formation, Wang et al. [5] and Simone et al. [6] developed a theoretical elasticity model of stress and deformation of wellbore structures that were under the effects of non-uniform ground stress and uniform internal pressure. However, the established model simplifies actual production conditions in quantity, thereby resulting in large errors between model analysis result and measured data. Therefore, Thiercelin et al. [7] used thermo-elasticity theory to perfect the thermo-elastic stress solution of a plane group object; they then studied the influence of cement sheathwellbore interfacial separation on wellbore structural integrity. The accuracy of the results of this study has greatly improved, but these findings are applicable to wellbore structural stability analysis under static loads only, and fluid seepage in actual production is not considered. Tang et al. [8] developed a stress distribution model of a horizontal well fracture casing-cement sheath-formation system in consideration of hydraulic fracture-induced stress field. However, this model considers the mechanical response of the wellbore under fluid pressure but not temperature influence. Chen et al. [9] established a collapse pressure calculation method using a weak bedding plane and analyzed the influence of well trajectory and weak bedding plane on wellbore stability. However, the presented method does not consider ground stress change during well drilling to collapse the conditions of a specific bedding plane. Considering the effect of hydration, Ding et al. [10] analyzed wellbore stability after contact between shale and drilling fluid and proposed a strength criterion suitable for mudstone. The criterion is applicable to wellbore stability analysis during well drilling, but the wellbore stress caused by the hardening of cement sheath during well cementing is not considered. Brandao et al. [11] presented a relatively perfect evaluation model of wellbore structural integrity, which they used to analyze the influences of initial in-situ stress and cementing pressure. However, the model does not consider the influences of cement hardening and formation pore pressure on wellbore stability. According to equivalent plastic strain criterion, Fan et al. [12] analyzed the relative variation of equivalent plastic strain of wellbore rock and formation pressure attenuation. Then, they investigated the relationship between critical differential pressure of production and attenuation of formation pressure. The influence of formation pressure change during production on wellbore stability is considered, but the influences of casing pipe and cement sheath are ignored. Aiming at the influence of wellbore construction and material nonlinearity on wellbore integrity, Li [13] analyzed six cases of wellbore failure with a multiphysical process numerical method. However, the load linkage in the drilling and cementing process is neglected, thereby failing to realize the whole wellbore loading course. Liu et al. [14] used triaxial mechanical test to simulate rock stress change in the drilling and unloading process and analyzed the influence of unloading on mechanical properties of mudstone. The relationship among cohesion, internal friction angle, and unloading range of mudstone was studied. However, the effect of cement hardening on wellbore stability is neglected.

Existing studies mainly focused on wellbore failure mechanism under internal pressure and temperature load in specific processes. They don't consider the loads in different stages and their sequential linkage during wellbore construction. Few studies have analyzed wellbore structural damage in the whole loading course. Plastic softening and elasticity modulus hardening models are used in the current study to describe constitutive relationship between soft mudstone formation and well cementing cement sheath. A numerical coupling model of casing pipe-cement sheath-soft mudstone is developed. Wellbore structural deformation and stress in well drilling, casing down, and cement hardening are analyzed, and the plastic damage evolution laws of formation near the wellbore and well cementing cement sheath are investigated. Based on the presented model, the influences of elasticity modulus and Poisson's ratio of cement sheath on wellbore structural stability are discussed. The results provide a certain reference for optimization of construction parameter and cement slurry system during drilling and cementing.

The remainder of this study is organized as follows. The numerical model of casing-cement sheath-wellbore structure is developed in section 3. Plastic damage evolution laws of mudstone near wellbore and well-cementing cement sheath are investigated, and the influences of elasticity modulus and Poisson's ratio of cement sheath on wellbore structural stability are discussed in Section 4. The present study is summarized, and relevant conclusions are drawn in the final section.

\section{Methodology}

Plastic softening and elasticity modulus hardening models are used to describe the constitutive relationship between soft mudstone and cement sheath formation. The numerical coupling model of casing-cement sheath-wellbore structure is then developed. Based on the model, the processes under sequential linkage, namely, well drilling, casing down, and cement hardening, are simulated. Stress and deformation of the wellbore structure in different stages are analyzed to provide data for discussing the wellbore failure mechanism and studying the evolution laws of wellbore structural damage.

\subsection{Constitutive model of soft mudstone and cement sheath formation}

\subsubsection{Plastic softening model of soft mudstone formation} Mudstone has remarkable plastic softening characteristics due to high confining pressure. Stress-strain curves are introduced in this study to describe elastic plastic behaviors of soft mudstone, as shown in Fig. 1.

Mohr-Coulomb (M-C) plastic strain softening model is adopted for plastic deformation or damage of $\mathrm{AB}$ segment, and $\mathrm{M}-\mathrm{C}$ yield function and rock strength softening model are combined to describe post-peak plastic softening behaviors of the medium. Function curve $F$ can be expressed as:

$$
F=\left(\sigma_{1}-\sigma_{3}\right)-\sin \varphi \cdot\left(\sigma_{1}+\sigma_{3}\right)-2 c \cdot \cos \varphi
$$


Where $\sigma_{1}$ is the maximum effective principal stress, $\sigma_{3}$ is the minimum effective principal stress, $c$ is the cohesion and $\varphi$ is the internal friction angle.

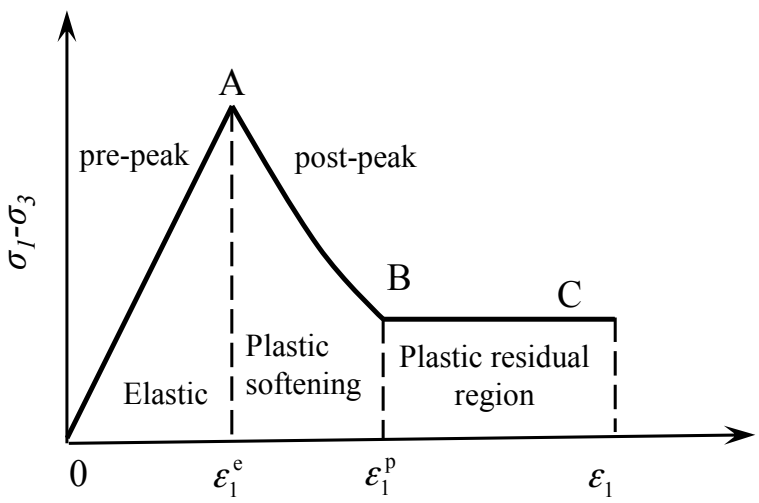

Fig. 1. Stress-strain constitutive relations of soft mudstone

In the rock strength softening model, cohesion $c$ and internal friction angle $\varphi$ of the rock gradually decrease as plastic strain increased, as expressed as below:

$$
\begin{aligned}
& c=\left\{\begin{array}{lr}
c_{0} & \varepsilon<\varepsilon_{1}^{\mathrm{e}} \\
c_{0}-M_{c}\left(\varepsilon-\varepsilon_{1}^{\mathrm{e}}\right) & \varepsilon_{1}^{\mathrm{e}} \leq \varepsilon<\varepsilon_{1}^{\mathrm{p}} \\
c^{*} & \varepsilon \geq \varepsilon_{1}^{\mathrm{p}}
\end{array}\right. \\
& \varphi=\left\{\begin{array}{lr}
\varphi_{0} & \varepsilon<\varepsilon_{1}^{\mathrm{e}} \\
\varphi_{0}-M_{\varphi}\left(\varepsilon-\varepsilon_{1}^{\mathrm{e}}\right) & \varepsilon^{\mathrm{e}} \leq \varepsilon<\varepsilon_{1}^{\mathrm{p}} \\
\varphi^{*} & \varepsilon \geq \varepsilon_{1}^{\mathrm{p}}
\end{array}\right.
\end{aligned}
$$

Where $c_{0}$ is Initial cohesion, $c^{*}$ is residual cohesion, $\varphi_{0}$ is initial internal friction angle, $\varphi^{*}$ is residual friction angle, $\varepsilon$ is total strain level, $\varepsilon_{1}^{\mathrm{e}}$ is elastic proportional limit strain, $\varepsilon_{1}^{\mathrm{p}}$ is plastic damage limit strain, $M_{c}$ is cohesion softening modulus and $M_{\varphi}$ is internal friction angle softening modulus.

\subsubsection{Elasticity modulus hardening model of cement}

Numerical changes in elasticity modulus are substantial during cement hardening, whereas those in Poisson's ratio are minor. Alber et al. [15] used sound velocity method to determine elasticity modulus change during cement hardening, as shown in Fig. 2. The Poisson's ratios of well cementing cements of $\mathrm{A}, \mathrm{B}$, and $\mathrm{C}$ models are $0.15,0.22$, and 0.286 , respectively.

In the cement hardening process, variable elasticity modulus parameters are used to analyze stress, which is shown in Fig. 2. The yield state is described by DruckerPrager function $f$ and cement stress is corrected.

$$
f=\sqrt{J_{2}}-\alpha I_{1}-k=0
$$

Where $I_{1}$ is the first invariant of stress tensor, and $J_{2}$ is the second invariant of stress deviation. $\alpha$ and $k$ are material parameters related to internal friction angle and cohesion.

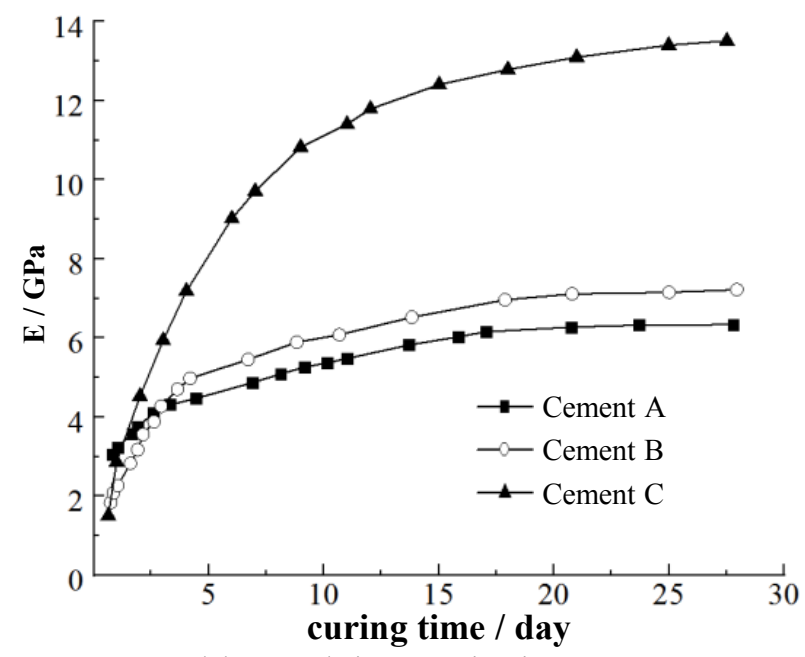

Fig. 2. Young modulus E evolution vs. curing time

\subsection{Particle representation}

\subsubsection{Finite element numerical model}

As shown in Fig. 4, the finite element numerical model of $1 / 4$ plane strain of cross-sectional wellbore $(x-y)$ is established because of complexity, according to the model of casing-cement sheath-formation structure shown in Fig. 3. The model size is $4 m \times 4 m$. The outer diameter of the casing, wellbore thickness, and the outer diameter of the cement sheath are $0.22 \mathrm{~m}, 0.01 \mathrm{~m}$, and $0.28 \mathrm{~m}$, respectively. The minimum and maximum horizontal principal stresses are along the $x$ and $y$ directions, respectively.

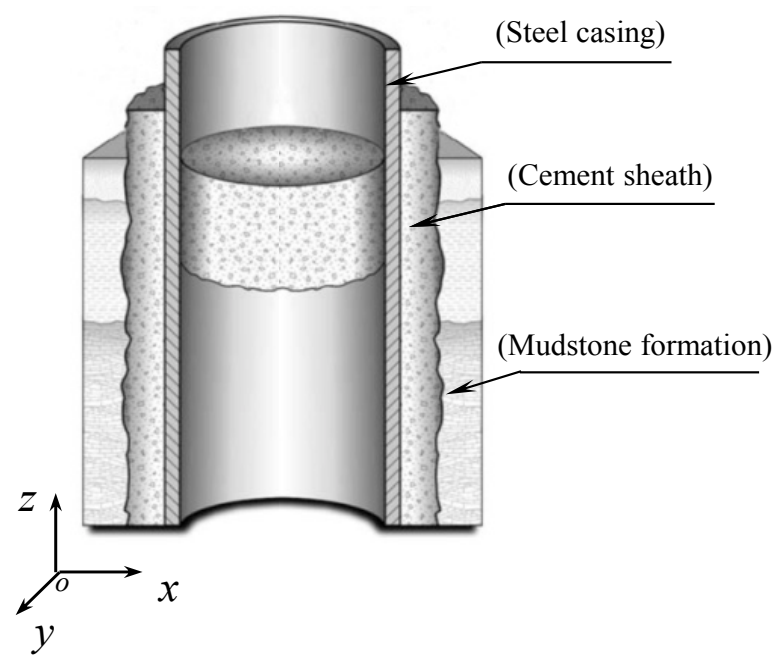

Fig. 3. The classical structure model of casing-cement sheath-wellbore

\subsubsection{Numerical simulation of multiple physical processes}

(1) Initial ground stress equilibrium

Initial ground stress, pore pressure, boundary condition, and material property are assigned to the whole model for ground stress equilibrium analysis. The equilibrium between material property and initial stress state is established to simulate the initial occurrence stress state of the formation. In this step, the numerical model contains only formation rocks, as shown in Fig. 4(a).

(2) Well drilling

In well drilling and unloading, wellbore area units are removed to simulate drilling and pore-forming process. Drilling fluid pressure is applied to the wellbore, as shown in Fig. 4(b). 
In seepage-stress coupling, the pore pressure boundary equal to drilling fluid pressure is defined on the wellbore, and a seepage analysis module is used to calculate fluid the seepage-stress coupling effect. Meanwhile, formation permeability undergoes dynamic correction during calculation, and pore fluid seepage process is simulated.

(3) Cementing process

Simulation of the well cementing process is divided into links, as shown in Fig. 4(c) and Fig. 4(d). In casing down, the units at casing are activated, and drilling fluid pressure $P_{w}$ is applied to the inside and the outside of the casing to simulate the process of casing down.

The process of cement injection is that: cement is firstly injected in the casing while wellbore friction is neglected.

According to the cement hardening model established in Section 2.2 , the elasticity modulus of well cementing cement increases with time during hardening, whereas the Poisson's ratio remains unchanged. Calculation is conducted in four time steps. Finally, a D-P plastic model is adopted for cement sheath activation and cementing, where cohesion and internal friction angles are constants, as shown in Table 1.

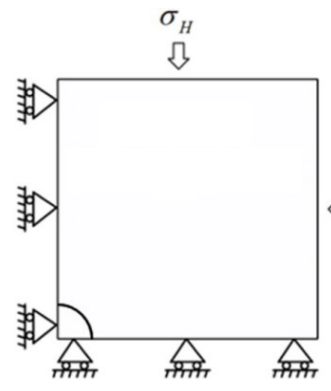

(a) Initial in-situ stress equilibrium

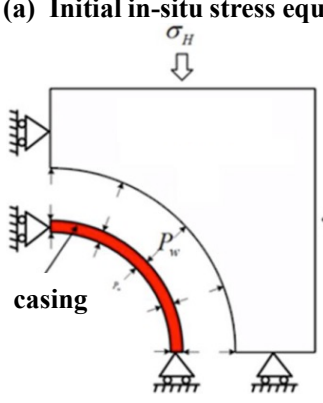

(c) Production phase

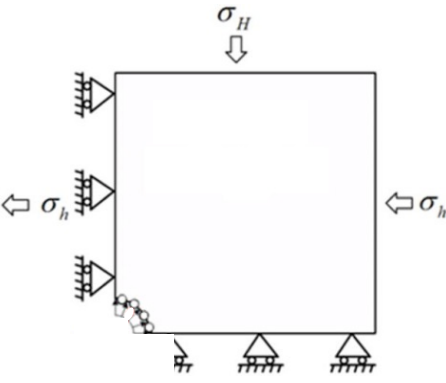

(b) Drilling process

$\Omega$

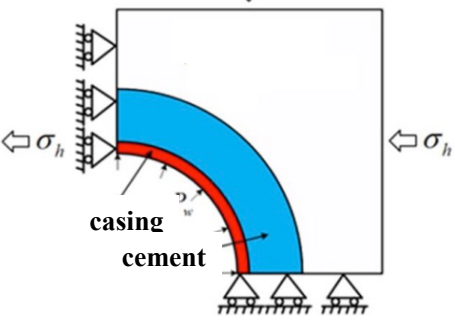

(d) Cementing process
Fig. 4. FEM numerical models and simulating procedure

Table 1. Parameters of soft mudstone and cement sheath

\begin{tabular}{c|c|c}
\hline Parameters & Mudstone & Cement Sheath \\
\hline Initial cohesion $/ \mathrm{MPa}$ & 3.0 & 2.0 \\
Residual cohesion /MPa & 0.2 & - \\
Initial angle of internal friction & 40 & 35 \\
$\left(^{\circ}\right)$ & & - \\
Residual angle of internal & 25 & - \\
friction $/\left(^{\circ}\right)$ & 0.005 & - \\
Critical elastic strain & 0.01 & - \\
Critial plastic strain &
\end{tabular}

\section{Result Analysis and Discussion}

4.1 Stress and plastic damage near wellbore during well drilling and cementing

Based on coupling numerical model of casing-cement sheath-wellbore structure established in section 3.2, a numerical analysis of formation stress distribution nearby wellbore in the well drilling and cementing process is conducted. Fig. 5(a) and Fig. 5(b) show radial and circumferential stress distribution changes in the direction of minimum horizontal principal stress (BC direction) in the formation near wellbore.

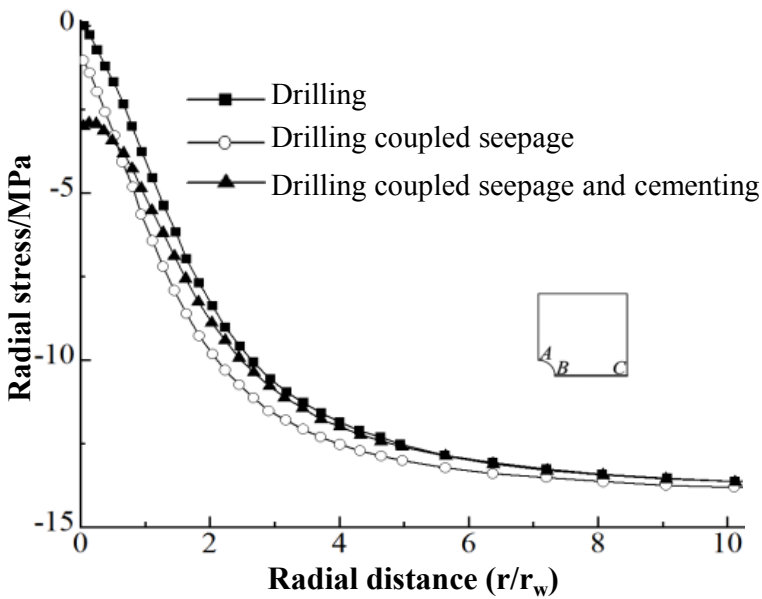

(a) Radial stress distribution along BC

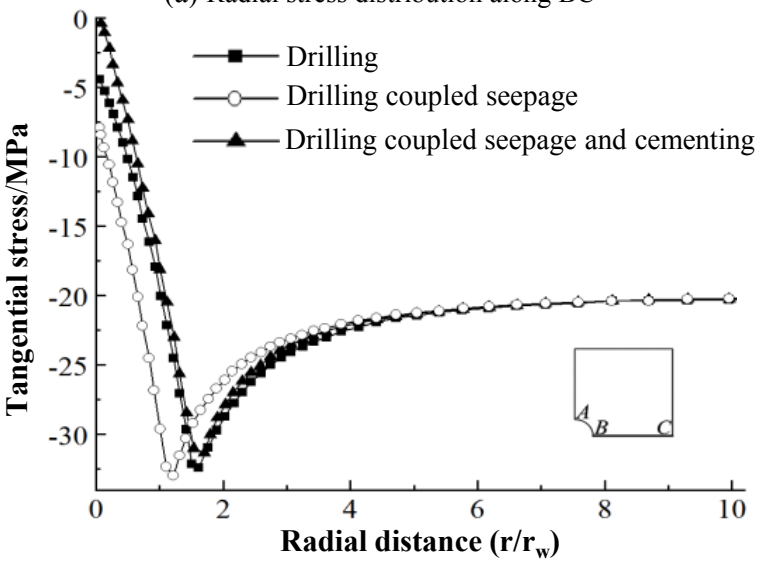

(b) Tangential stress distribution along BC

Fig. 5. Radial and tangential stress distribution near wellbore region

In well drilling, the circumferential stress reaches its maximum distance from the wellbore at $1.1 r_{w}$ because of stress concentration during drilling unloading. Thereafter, the radial and the circumferential stresses are locally adjusted and redistributed due to the seepage coupling effect between the mudstone and drilling fluid. The peak value of the circumferential stresses gradually moves out to reach a distance of $1.6 r_{w}$ from the wellbore.

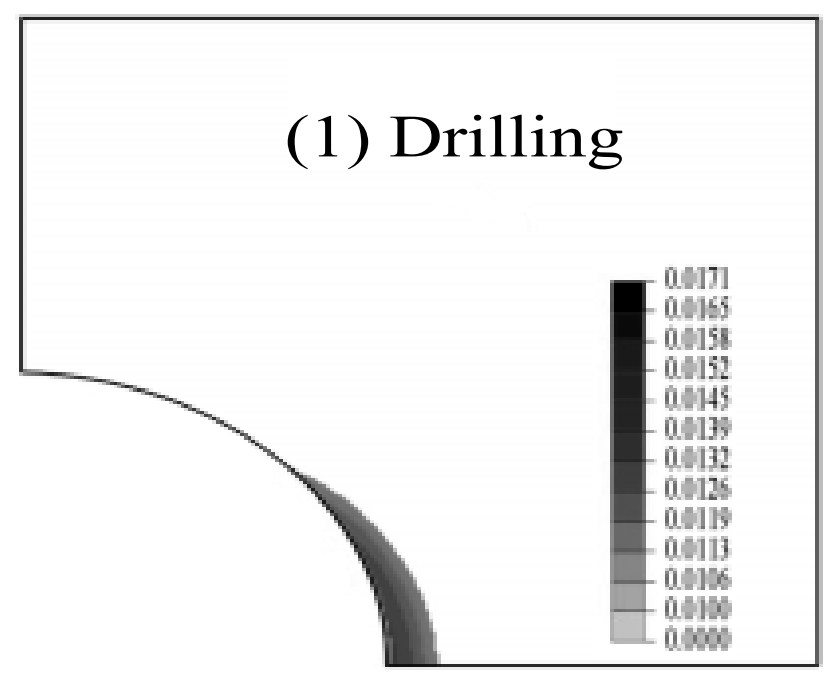

(a) Plastic damage near wellbore during drilling process 


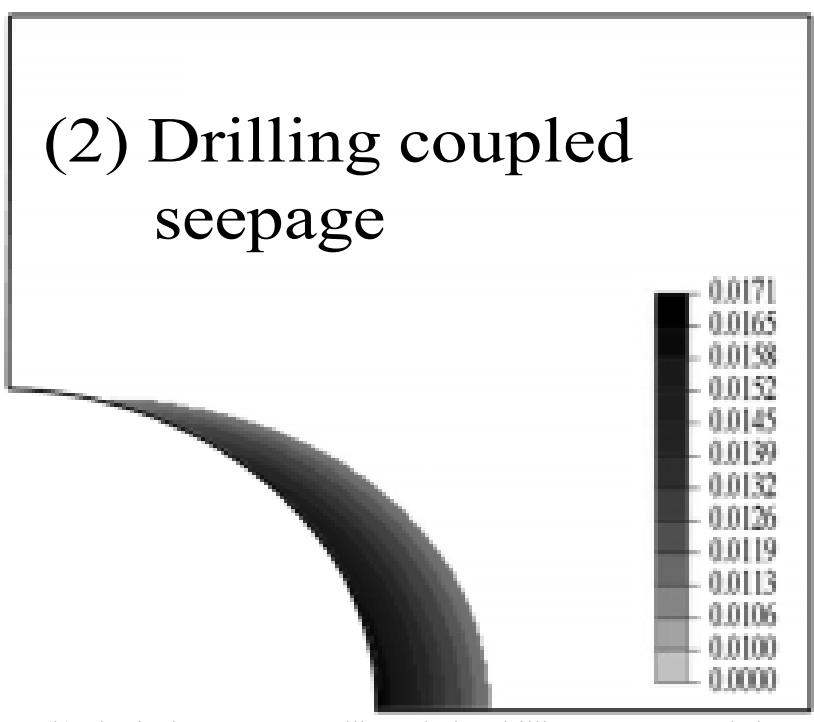

(b) Plastic damage near wellbore during drilling process coupled seepage

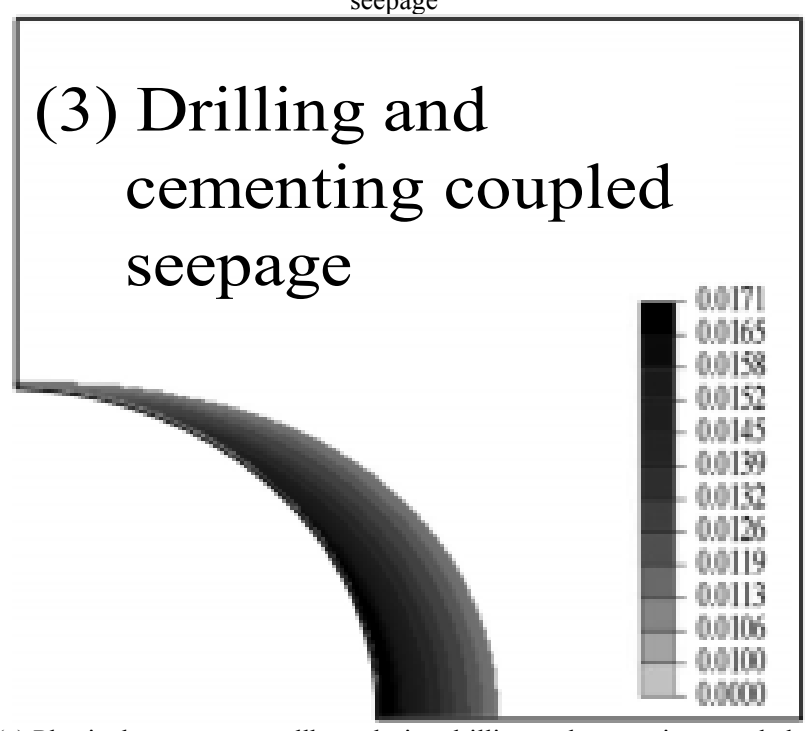

(c) Plastic damage near wellbore during drilling and cementing coupled seepage

Fig. 6. Plastic damage zone near wellbore region

Equivalent plastic strain is used to characterize the plastic damage of the soft mudstone formation. The critical equivalent plastic strain, that is, the equivalent plastic strain needed for the material to generate plastic damage, is defined as $1 \%$ [17]. According to a comparison of the distribution ranges of the plastic damage zones near the wellbore, which is shown in Fig. 6(a) and Fig. 6(b), the stress distribution and plastic damage degree of the soft mudstone wellbore are greatly influenced by seepage or stress coupling effect. The plastic damage zone near wellbore expands considerably. The range of seepageinduced damage zone reaches 0.5 times the wellbore radius in Fig. 6(b) relative to that in Fig. 6(a). Hence, sophisticated regulation technology should be adopted during well drilling calculation.

Pressure load fluctuation occurring in the cementing stage has a certain influence on the degree of plastic damage of the formation near the wellbore. The range of plastic damage generated by well cementation in Fig. 6 (c) is higher by approximately 10 times than that in Fig. 6(b). Therefore, well drilling and the seepage-stress coupling effect are the main factors that control and influence the stress distribution of mudstone wellbore. The influence on stress distribution near the wellbore is minor during well cementing, whereas the influence on the plastic deformation-induced damage degree is significant.

\subsection{Evolution laws of cement sheath stress during well cementing}

Based on the numerical coupling model of casing-cement sheath-wellbore structure established in section 3.2, a numerical analysis of stress change in the formation near wellbore during cement sheath hardening process is conducted. Four cement hardening time points are selected for fine analysis. These time points are initial (activated), 1st day, 2nd day, and 28th day stiffness. Elasticity modulus values corresponding to the time points are selected and substituted into the constitutive Equation (4), and all Poisson's ratios are taken as 0.286 of C-type cement.

In the model, the elasticity modulus of the cement sheath changes from $1.5 \mathrm{GPa}$ at initial activation to $13.5 \mathrm{GPa}$ on the 28th day. As the cement sheath stiffness gradually increases, stress change in the formation near the wellbore is minor, except for the stress at the secondary cement sheathformation interface, as shown in Fig. 7(a) (radial stress) and Fig. 7(b) (circumferential stress), which are identical with the results in Fig. 5. The results indicate that the deformation of cement sheath is not enough to influence stress distribution near wellbore when thickness is $3 \mathrm{~cm}$. Local cement hardening effect might not be considered during stability analysis for wellbore structure.

During well cementing, cement sheath hardening is actually a process of gradually establishing the stiffness and bearing pressure loads of casing and formation. Fig. 7 shows stress evolution of the cement sheath structure. The elasticity modulus of cement sheath gradually increases during hardening, and two-way compressive stress on cement sheath structure in the annular between casing and wellbore is enhanced. In addition, the radial compressive stress of the cement sheath increases, as shown in Fig. 7(a). The radial compressive stress at the primary interface (cement sheathcasing) is obviously higher than that at the secondary interface (cement sheath-formation). The gradient and nonuniformity of radial compressive stress inside the cement sheath causes circumferential tensile stress at the primary interface, as shown in Fig. 7(b). Approximately 4.0 MPa circumferential tensile stress is generated at the primary interface after 28 days of cement sheath hardening. Radial tension fissures might develop from inside to outside, which goes against the airtightness of cement sheath and the follow-up production and operation of the wellbore structure.

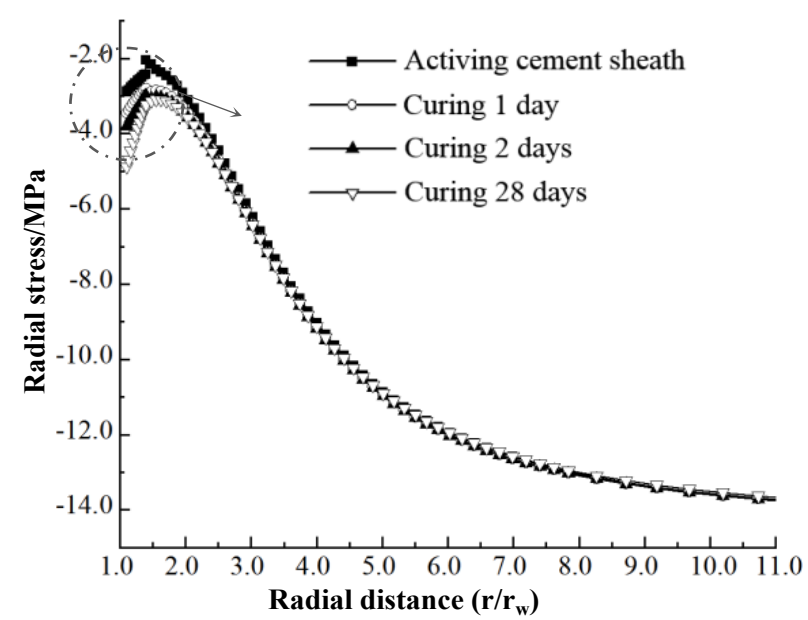

(a) Radial stress distribution along BC 


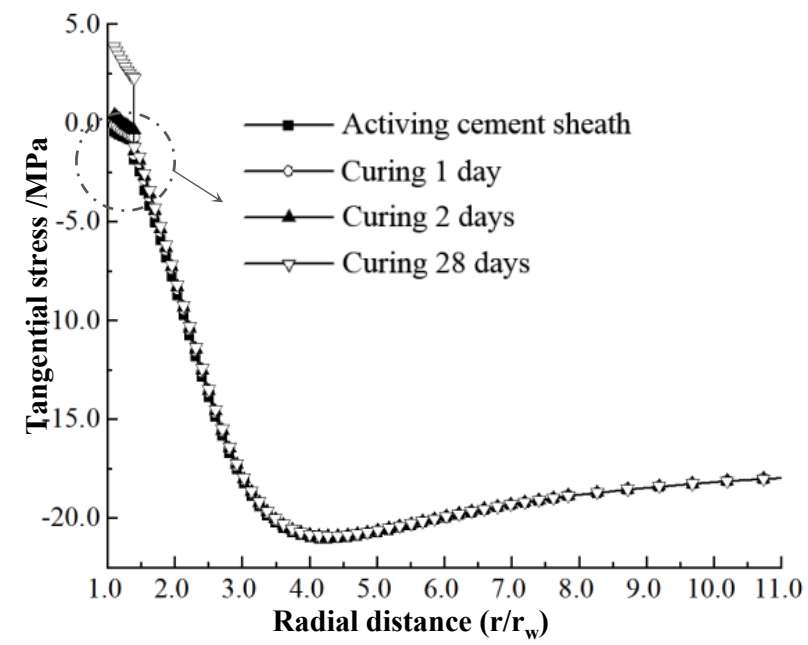

(b) Tangential stress distribution along BC

Fig. 7. Stress evolution of near wellbore region and cement sheath during cement hardening period

As elasticity modulus increases in the well cementing process, radial compressive stress and circumferential tensile stress of the cement sheath both significantly increase, and both of which reach maximum values at the primary interface. Meanwhile, plastic deformation of the cement sheath could adjust the stress distribution and reduce stress gradient or non-uniformity. Therefore, cement paste system with small elasticity modulus is recommended in the well cementing construction process.

Furthermore, plastic deformation damage is generated in the high-stress zone due to radial compressive and circumferential tensile stresses, which present non-uniform distribution along the thickness direction of the cement sheath, as shown in Fig. 8. The equivalent plastic strain at the primary interface reaches $0.24 \%$.

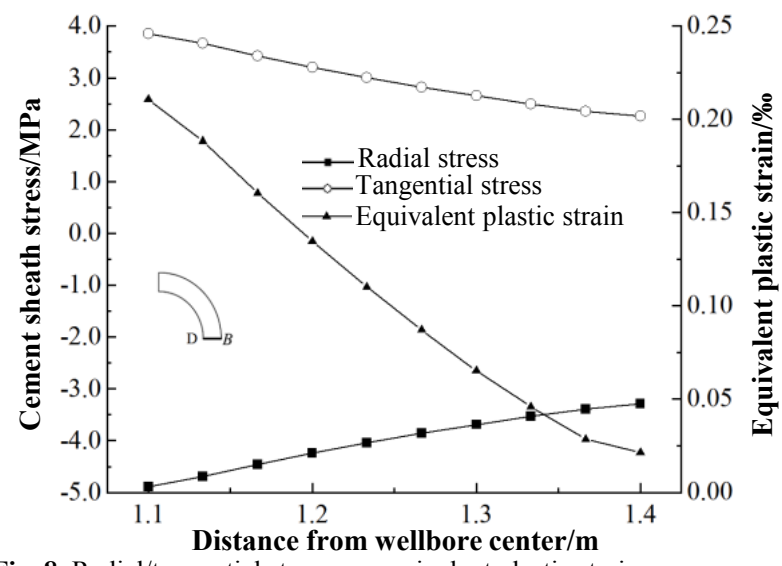

Fig. 8. Radial/tangential stress vs. equivalent plastic strain

\subsection{Influence of Poisson's ratio of the cement sheath}

Three typical cement slurry systems in Section 2.2 are selected. The Poisson's ratios of these systems are $0.15,0.22$, and 0.286 . Elasticity modulus of well cementing cement is unchanged, and the value is $13.5 \mathrm{GPa}$.

Poisson's ratio is a mechanical index reflecting compatibility of material deformation, and Poisson's ratio of tough material is higher.

Figs. 9(a) and 9(b) show the radial and circumferential stress distributions of the cement sheath when their Poisson' s ratios are different. As Poisson's ratio increases, radial stress of the cement sheath is adjusted to a certain degree but not substantially. Circumferential stress reduces by about $0.6 \mathrm{MPa}$ as Poisson's ratio increases at a significant level, thereby restraining the generation of tensile cracks at the primary interface.

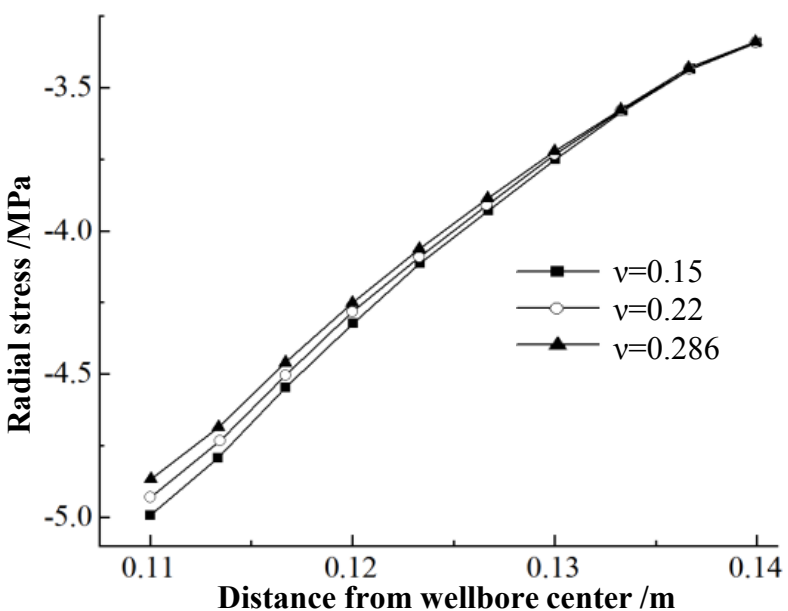

(a) Radial stress distribution along the path DB

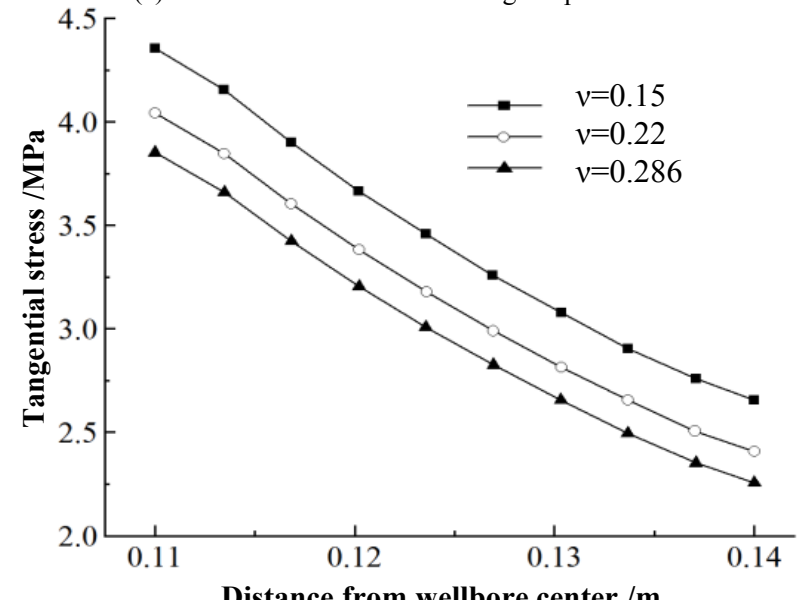

(b) Tangential stress distribution along the path DB

Fig. 9. Effects of Poisson ratio on radial/tangential stress

\section{Conclusions}

To describe the failure mechanism of wellbore structural and influence factors of its integrity during well drilling and cementing, a numerical method of multiple physical processes was used to analyze the deformation and stress evolution of soft mudstone formation and cement sheath. The model was presented from the viewpoint of plastic deformation, stress distribution of the formation near the wellbore, and evolution of hardening stress of cement sheath. The following conclusions could be drawn.

(1) During well drilling, drilling-induced borehole and seepage-stress coupling effect are important to control wellbore structural stability in soft mudstone formation. Cement hardening can further promote plastic damage of the formation near wellbore with $10 \%$ growth range.

(2) During cement hardening, high radial compressive stress occurs at the primary interface of casing-cement sheath, which results in circumferential tensile stress. Circumferential tension stress is prone to producing tension cracks, thereby leading to wellbore seal failure and leakage.

(3) By adjusting the formulation of cement slurry system, the toughness of cementing cement material can be enhanced in many ways, such as reducing elastic modulus and increasing Poisson's ratio, which are beneficial to reduce 
the risk of circumferential tensile failure and maintain the integrity of cement sheath.

As the key link of connecting casing and mudstone wellbore, cement has to meet the requirements of inheriting the mechanical strength of compressive load between casing and formation, coordinating the deformation, maintaining the integrity, and sealing of the first and second interfaces, among others. Deformation and failure mechanism are extremely complex. Therefore, in view of the specific wellbore temperature and pressure loading environment, a fine mechanical analysis of deformation characteristics of the cement sheath should be conducted by combining physical model tests and numerical simulations. Results are beneficial to achieving the best matching of the strength and toughness of cement material and providing theoretical support for improving the process design of cement slurry material system.

This is an Open Access article distributed under the terms of the Creative Commons Attribution License

\section{References}

1. King, G. E., King, D. E., "Environmental risk arising from wellconstruction failure-differences between barrier and well failure, and estimates of failure frequency across common well types, locations, and well age". Society of Petroleum Engineers Production \& Operations, 28(4), 2013, pp.323-344.

2. Xi, Y., Li, J., Liu, G., Tao, Q., Lian, W., "A new numerical investigation of cement sheath integrity during multistage hydraulic fracturing shale gas wells". Journal of Natural Gas Science and Engineering, 49, 2018, pp.331-341.

3. Elaheh, A., Terry, B., Giang, D. N., "Evaluation of cement sheath integrity subject to enhanced pressure". Journal of Petroleum Science and Engineering, 170, 2018, pp.1-13.

4. Goodwin, K. J., Crook, R. J., "Cement sheath stress failure". Society of Petroleum Engineers Drilling Engineering, 7(4), 1992, pp. 291296.

5. Wang, Y., Gao, D., Fang, J., "Mechanical characteristics analysis of casing-cement ring-formation multilayer composite system". Chinese Journal of Applied Mechanics, 31(3), 2014, pp.387-389.

6. Simone, M. D., Pereira, F. L. G, Roehl, D. M., "Analytical methodology for wellbore integrity assessment considering casingcement-formation interaction". International Journal of Rock Mechanics \& Mining Sciences, 94, 2017, pp.112-122.

7. Thiercelin, M. J., Dargaud, B., Baret, J. F., Rodriguez, W. J., "Cement design based on cement mechanical response". Society of Petroleum Engineers Drilling \& Completion, 13(4), 1998, pp.266273.

8. Tang, Z., Li, Q., "Stress analysis of cement sheath of horizontal well during hydraulic fracturing". Chinese Journal of Applied Mechanics, 35(3), 2018, pp.551-55.
9. Chen, Z., Wang, Q., Zhang, Y., "Wellbore stability analysis considering weak bedding plane". Chinese Journal of Underground Space and Engineering, 12(2), 2016, pp.632-638.

10. Ding, Y., Liu, X., Luo, P., Liang, L., "Analysis of the wellbore stability in mud shale formations based on the parabolic strength criterion". Petroleum Geology and Oilfield Development in Daqing, 37(5), 2018, pp.160-167.

11. Brandao, N., Roehl, D., "Modelling cement hardening in pre-salt wells". In: $50^{\text {th }}$ U.S. Rock Mechanics / Geomechanics Symposium, Houston, Texas, USA: ARMA, 2016, pp.1-6.

12. Fan, Z., "Effect of Formation Pressure Decay on Wellbore Stability in Horizontal Wells". Journal of Chongqing University of Science and Technology (Natural Science Edition), 19(2), 2017, pp.51-53.

13. Li, X., Jaffal, H., Feng, Y., Mohtar, C. E., Gray, K. E., "Wellbore breakouts: Mohr-Coulomb plastic rock deformation, fluid seepage, and time-dependent mudcake buildup". Journal of Natural Gas Science and Engineering, 52, 2018, pp.515-528.

14. Liu, X., Ding, Y., Luo, P., Liang, L., "The impact of drilling unloading on wellbore stability of shale formations". Petroleum Drilling Techniques, 46(1), 2018, pp.10-16.

15. Alber, M., Ehringhausen, N., "Petrophysical properties of casing cement while curing". Procedia Engineering, 191, 2017, pp.64-171.

16. Zhang, P., Sun, F., Ye, G., "Analysis of the wellbore stability based on plastic damage theory in soft shale formation". Mechanics in Engineering, 40(3), 2018, pp.273-280.

17. Li, X., EI Mohtar, C. S., Gray, K. E., "Numerical modeling of borehole breakout in ductile formation considering fluid seepage and damage-induced permeability change". In: $50^{\text {th }}$ U.S. Rock Mechanics / Geomechanics Symposium, Houston, Texas, USA: ARMA, 2016, pp.10-20. 